\title{
Candidates for Bariatric Surgery: Morbidly Obese Patients with Pulmonary Dysfunction
}

\author{
Yu-Feng Wei ${ }^{1}$ and Huey-Dong $\mathrm{Wu}^{2}$ \\ ${ }^{1}$ Department of Internal Medicine, E-Da Hospital, I-Shou University, Kaohsiung 824, Taiwan \\ ${ }^{2}$ Department of Internal Medicine, National Taiwan University Hospital, Taipei 100, Taiwan \\ Correspondence should be addressed to Huey-Dong Wu, hdwuntuh@ntu.edu.tw
}

Received 29 November 2011; Accepted 26 March 2012

Academic Editor: Natan Zundel

Copyright (C) 2012 Y.-F. Wei and H.-D. Wu. This is an open access article distributed under the Creative Commons Attribution License, which permits unrestricted use, distribution, and reproduction in any medium, provided the original work is properly cited.

\begin{abstract}
Obesity is a well-known major risk factor of cardiovascular disease and is associated with various comorbidities. The impact of obesity on pulmonary function remains unclear. Reductions in chest wall compliance and respiratory muscle strength due to a high percent body fat and localized fat distribution contributes to impaired pulmonary function and the occurrence of adverse respiratory symptoms. Dietary modifications and pharmaceutical agents are not effective in the long-term treatment of obesity. Treatment of morbidly obese patients using bariatric surgery has increased each year, especially after the introduction of video laparoscopic techniques. Effective weight loss after bariatric surgery may improve cardiovascular disease risk factors, including diabetes, hypertension, dyslipidemia, atherosclerosis, inflammation, chronic kidney disease, obstructive sleep apnea, and obesity hypoventilation syndrome. Bariatric surgery has also been associated with significantly improved respiratory symptoms and pulmonary function. We currently present a review of principal studies that evaluated the effects of obesity on pulmonary function and the identification of anthropometric factors of obesity that correspond to the reversal of respiratory symptoms and impaired pulmonary function after bariatric surgery.
\end{abstract}

\section{Introduction}

The prevalence of obesity has increased worldwide in both developing and developed countries [1]. The majority of long-term epidemiologic studies have shown that obesity is associated with increased comorbidities such as cardiovascular disease, metabolic disorders, diabetes, cancer, chronic kidney disease (CKD), and immunologic dysfunction [24]. Obesity has also been shown to negatively impact the respiratory system and pulmonary function; as well as, being associated with obstructive sleep apnea syndrome (OSAS), obesity hypoventilation syndrome (OHS), and obstructive airway disease [4-6]. Several studies have demonstrated that weight reduction, as a result of dietary modification or surgical intervention, can improve organ dysfunction, health-related quality of life (HRQoL), and overall mortality [3, 7-9].

Bariatric surgery, with dual mechanisms of gastric volume restriction and malabsorption, has been recommended with increasing frequency to treat patients considered morbidly obese $[10,11]$. Bariatric surgery affords a rapid, sustained, and safe (operative mortality at 30 or less days was $0.1-1.1 \%$ ) procedure for effective weight reduction in morbidly obese individuals [7]. Bariatric surgery may improve the overall risk and incidence of cardiovascular disease, diabetes, hyperlipidemia, hypertension, atherosclerosis, inflammation, OHS, and OSAS [7, 12-14]. Bariatric surgery has also been suggested to improve asthma control and reduce the need for pharmacologic interventions [1316]. Furthermore, there is increasing evidence that bariatric surgery is associated with a significant improvement in respiratory symptoms and pulmonary function [17-25]. Improvements in pulmonary function may be due to a decrease in intra-abdominal pressure, which lends support to the hypothesis that individuals with abdominal obesity may be proper candidates for bariatric surgery in order to improve pulmonary function [25]. 
TABLE 1: Respiratory complications of obesity.

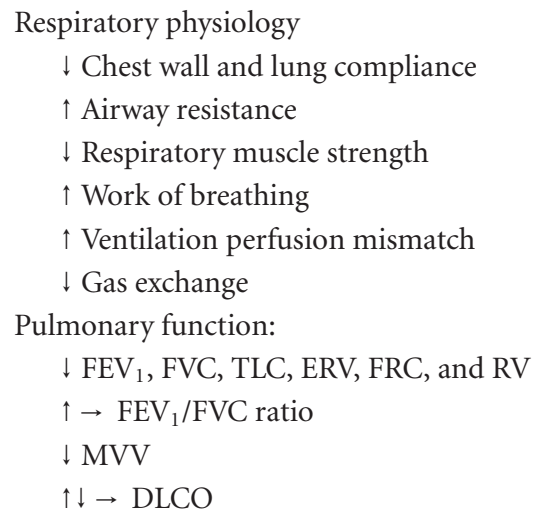

$\mathrm{FEV}_{1}$ : forced expiratory volume in the first second; FVC: forced vital capacity; TLC: total lung capacity; FRC: functional residual capacity; ERV: expiratory reserve volume; RV: residual volume; MVV: maximal voluntary ventilation; DLCO: diffusing capacity of the lung for carbon monoxide.

$\uparrow:$ increased; $\downarrow$ : decreased; $\rightarrow$ : no change.

\section{Obesity and Pulmonary Physiology}

Obesity has a profound effect on the physiology of breathing, including respiratory mechanics, airway resistance, respiratory muscle function, lung volume, work of breathing (WOB), and gas exchange [5]. A summary of complications associated with obesity is presented in Table 1. Patients classified as morbidly obese typically present with increased metabolic demands due to the additional work required for activities of daily living and to overcome the increased WOB. Elevated WOB is a result of reduced chest wall compliance, commonly associated with the accumulation of fat in and around the chest wall, the diaphragm, and the abdomen [6]. Obesity may also cause a reduction in lung volume, peripheral airway diameter, and alterations in pulmonary blood volume, which may result in a reduction in lung compliance. Reduced respiratory compliance has been shown to result in an increased oxygen cost of breathing; as well as, an increased respiratory drive, both of which may increase dyspnea [21, 26]. Numerous publications have demonstrated an association between obesity and obstructive lung disease, especially asthma. An epidemiological connection between obesity and obstructive lung disease has been described - a meta-analysis has shown that obesity is associated with the incidence of asthma, independent of gender [27]. Airway inflammation, narrowing of the peripheral airways, increased respiratory resistance, and extrapulmonary trigger/aggravating factors, such as gastroesophageal reflux or sleep disordered breathing (SDB), have been proposed as explanations for the increased incidence of obstructive pulmonary disease in obese patients [6].

Body mass index (BMI) can be used to rapidly classify individuals as obese. However, there is increasing evidence that a central pattern of fat distribution (central or abdominal obesity), indicated by a larger waist circumference (WC), waist-to-hip ratio (WHR), or waist-to-height ratio (WHtR), has profoundly more negative effects on the respiratory system than other anthropometric measurements of obesity
[28-33]. It has been suggested that abdominal obesity can cause an increase in abdominal and diaphragmatic pressure, altered pleural pressure, and a subsequent decrease in total lung capacity, pulmonary compliance, and pulmonary volume [34]. Sugerman et al. reported a correlation between increased abdominal pressure and WC or sagittal abdominal diameter $(r=0.74,0.78)$, which was primarily responsible for obesity hypoventilation due to elevation of the diaphragm [35]. Lambert et al. also showed that intraabdominal pressure correlated to the sagittal abdominal diameter, an index of the degree of central obesity, but not body weight or BMI [36].

\section{Obesity and Pulmonary Function}

A longitudinal study suggested that a restrictive pattern assessed with a single spirometric test was associated with increased morbidity and mortality [37]. It has been widely reported that obesity can lead to restrictive pulmonary function. This is evidenced by reductions in forced expiratory volume in the first second $\left(\mathrm{FEV}_{1}\right)$, forced vital capacity (FVC), expiratory reserve volume (ERV), residual volume (RV), and total lung capacity (TLC) $[5,6,29,31,38-40]$. However, the $\mathrm{FEV}_{1} / \mathrm{FVC}$ ratio was preserved or increased in these studies. In addition, several studies have shown that excess weight or simple weight gain is associated with pulmonary dysfunction [41-44]. Chen and colleagues analyzed pulmonary function in 1202 healthy adults in a 6-year follow-up study and reported a decline in both $\mathrm{FVC}$ and $\mathrm{FEV}_{1}$ after simple weight gain in both men and women. The effect of weight gain on pulmonary dysfunction has been shown to be greater in men than in women. Using a multiple regression analysis, each kilogram of weight gain was associated with reduced FVC $(-26 \mathrm{~mL})$ and $\mathrm{FEV}_{1}(-23 \mathrm{~mL})$ in men, and $-14 \mathrm{~mL}$ and $-9 \mathrm{~mL}$ in women, respectively [44]. The impaired pulmonary function may result from air-flow limitations, due to a reduction in the peripheral airway, and an increased abdominal load that alters chest wall mechanics [35, 43, 45]. The increased abdominal pressure may play a greater role in impaired pulmonary function and was suggested to be responsible for the elevation of the diaphragm, thereby producing a restrictive, rather than obstructive, pulmonary dysfunction [35]. An increasing number of studies have also supported the hypothesis that abdominal fat deposition is predictive of impairments in pulmonary function, moreso than BMI [29-32]. Ochs-Balcom et al. conducted a population-based study that assessed the association between pulmonary function and markers of adiposity and body fat distribution, including body weight, BMI, WC, WHR, and abdominal height. Their results suggested that abdominal adiposity (WC, abdominal height) is a better predictor of pulmonary dysfunction than weight or BMI [29]. Additional studies in different ethnic populations from Canada, the United Kingdom, and Taiwan have also demonstrated that WC is significantly associated with decreased $\mathrm{FEV}_{1}$ and FVC $[28,40,46]$.

Maximum voluntary ventilation, a reflection of respiratory muscle endurance and lung mechanics, has been 


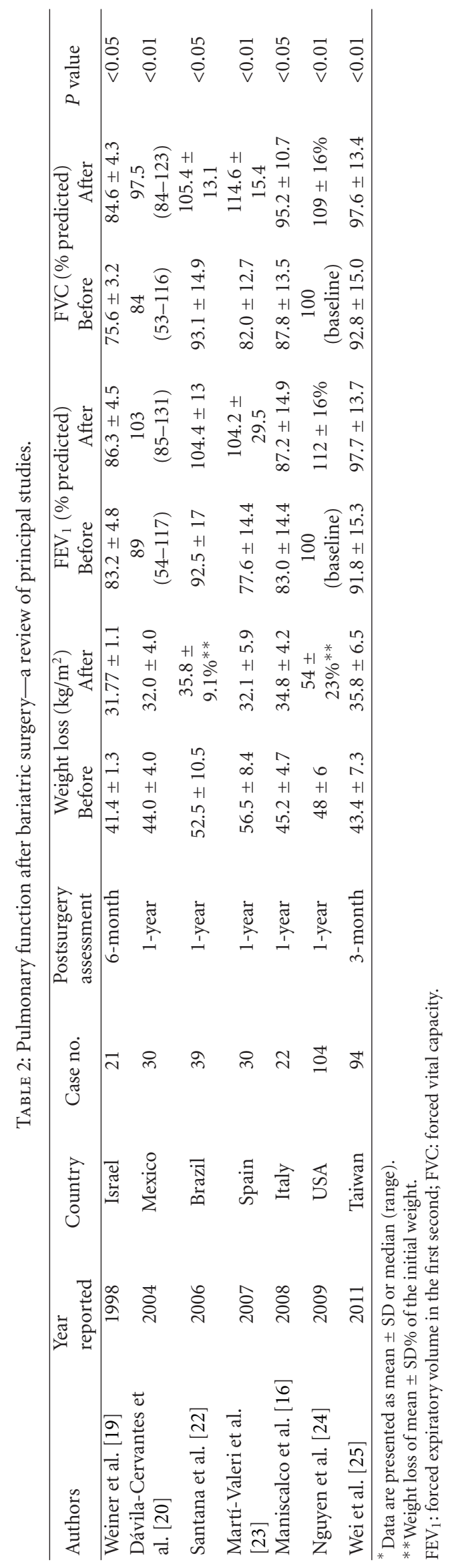


shown to decrease as BMI increases $[47,48]$. The reduction in endurance may be related to increased peripheral airway resistance, reduced chest wall compliance and muscle strength, or breathing at low lung volumes [19, 48]. The effect of obesity on gas exchange, which is commonly assessed by diffusion capacity of the lung for carbon monoxide (DLCO), is heterogeneous, and the exact pathophysiological mechanism leading to changes in DLCO remains unclear. Patients classified as obese who present with no clinically apparent heart disease may have a high output state and elevated total- and central-blood volumes, which will increase capillary blood volume, and thereby cause elevations in DLCO [38]. Reduced DLCO has also been observed in obese individuals, which may be due to structural changes in the interstitium of the lung as a result of lipid deposition, alveolar enlargement, cellular hyperplasia, and/or decreased alveolar surface area $[5,49]$.

Sekhri et al. examined the influence of gender and age on pulmonary function in morbidly obese patients [39] results showed that being male was associated with a greater negative impact on pulmonary function, and subjects aged greater than 40 years had significantly lower FVC and $\mathrm{FEV}_{1} / \mathrm{FVC}$ than those aged less than 40 years. The differential distribution of body fat in men and women, and the direct correlation between abdominal obesity and increasing age may explain Sekhri's results $[50,51]$.

\section{Effect of Bariatric Surgery on Pulmonary Function}

The use of surgical procedures for weight-loss when treating morbidly obese individuals has increased dramatically since 1998, especially after the introduction of video laparoscopic techniques (Table 2). Bariatric surgery for individuals considered severely obese has been shown to be associated with decreased comorbidities, reversed the respiratory complications associated with obesity, and reduced allcause mortality [9]. Several studies conducted in the 1980s reported that weight loss following gastric bypass surgery decreased abdominal pressure and sagittal abdominal diameter resulting in a reduction in pulmonary function and respiratory comorbidities, such as SDB, OHS, and OSAS $[17,52]$. Increasing evidence has been become available that emphasizes improved pulmonary function after bariatric surgery [16-24]. Sugerman et al. demonstrated significantly improved lung volumes in 26 patients with OHS after gastric bypass surgery [17]. Thomas et al. reported similar results following weight loss surgery-in 29 patients, a small but significant rise in FVC $(7 \% ; P=0.002)$ and $\mathrm{FEV}_{1}(6 \% ; P=$ 0.017 ) after a mean weight loss of $34.2 \mathrm{~kg}$ (range: $2-64 \mathrm{~kg}$ ) [18]. Weiner et al. has reported significant increases in FVC in 21 morbidly obese patients following weight loss surgery, with no significant change in $\mathrm{FEV}_{1}$ and $\mathrm{FEV}_{1} / \mathrm{FVC}$ ratio [19]. Dávila-Cervantes et al. described 30 morbidly obese patients with improved $\mathrm{FEV}_{1}(89 \%$ to $103 \%)$ and $\mathrm{FVC}(84 \%$ to $97.5 \%$ ) one year after vertical banded gastroplasty [20]. Similarly, Martí-Valeri et al. examined 30 patients with improved $\mathrm{FEV}_{1}(78 \%$ to $104 \%)$ and FVC (82\% to $\left.115 \%\right)$ one year after gastric bypass surgery [23]. Maniscalco et al. also reported an improvement in $\mathrm{FEV}_{1}$ (83\% to $87 \%$ ) and FVC (88\% to 95\%) in 12 obese females with asthma one year after gastric bypass surgery [16]. In a study conducted by Santana et al., FVC and $\mathrm{FEV}_{1}$ were significantly improved in 39 patients following weight-loss surgery. Pulmonary function was improved to a greater extent in patients considered severely morbidly obese (BMI $\geq 60 \mathrm{~kg} / \mathrm{m}^{2}$ ) compared with less morbidly obese patients (BMI: $40-59.9 \mathrm{~kg} / \mathrm{m}^{2}$ ) [22]. Nguyen et al. examined pulmonary function in 104 morbidly obese patients who underwent either laparoscopic gastric bypass or gastric banding. Restrictive and obstructive respiratory mechanics associated with obesity were significantly improved after surgically induced weight loss and were observed as early as three months after surgery [24]. A recent study conducted by Wei et al. showed that each kilogram of body weight lost aftersurgery was associated with an improvement of $0.28 \%$ $(9.4 \mathrm{~mL})$ in $\mathrm{FEV}_{1}$ and $0.23 \%(9.1 \mathrm{~mL})$ in FVC. In addition, reduced WC was associated with a reversal of impaired pulmonary function - with each centimeter of WC reduction $\mathrm{FEV}_{1}$ and FVC increased by $0.44 \%(14.8 \mathrm{~mL})$ and $0.36 \%$ $(14.3 \mathrm{~mL})$, respectively [25]. In a previous study reported by Zavorsky et al., DLCO was found to improve within 10 weeks of bariatric surgery and was strongly associated with changes in alveolar volume and WHR, an indicator of central obesity [53]. Lastly, a study reported by Oppenheimer et al. showed significant distal airway dysfunction, as detected by impulse oscillometry, in obese subjects despite normal spirometric findings. These abnormalities were significantly improved after bariatric surgery [54].

\section{Summary}

Therapeutic interventions need balance efficacy against risk. Bariatric surgery is a rapid, sustained, and safe surgical procedure for effective weight reduction in morbidly obese individuals. Overall, effective weight loss by bariatric surgery has been demonstrated to be associated with improved pulmonary function. Individuals with larger WC may be candidates for bariatric surgery in an effort to reverse impaired pulmonary function. Identification of patients who will benefit the most from bariatric surgery to improve other symptoms and clinical associations, such as dyspnea, asthma, OHS, or OSAS, is warranted and requires future investigation.

\section{Conflict of Interests}

Y.-F. Wei and H.-D. Wu have no conflict of interests or financial ties to disclose.

\section{References}

[1] M. Deitel, "Overweight and obesity worldwide now estimated to involve 1.7 Billion people," Obesity Surgery, vol. 13, no. 3, pp. 329-330, 2003.

[2] B. Conway and A. Rene, "Obesity as a disease: no lightweight matter," Obesity Reviews, vol. 5, no. 3, pp. 145-151, 2004. 
[3] S. D. Navaneethan, H. Yehnert, F. Moustarah, M. J. Schreiber, P. R. Schauer, and S. Beddhu, "Weight loss interventions in chronic kidney disease: a systematic review and meta-analysis," Clinical Journal of the American Society of Nephrology, vol. 4, no. 10, pp. 1565-1574, 2009.

[4] N. Leone, D. Courbon, F. Thomas et al., "Lung function impairment and metabolic syndrome the critical role of abdominal obesity," American Journal of Respiratory and Critical Care Medicine, vol. 179, no. 6, pp. 509-516, 2009.

[5] S. M. Koenig, "Pulmonary complications of obesity," American Journal of the Medical Sciences, vol. 321, no. 4, pp. 249-279, 2001.

[6] A. S. Jubber, "Respiratory complications of obesity," International Journal of Clinical Practice, vol. 58, no. 6, pp. 573-580, 2004.

[7] H. Buchwald, Y. Avidor, E. Braunwald et al., "Bariatric surgery: a systematic review and meta-analysis," Journal of the American Medical Association, vol. 292, no. 14, pp. 1724-1737, 2004.

[8] M. De Zwaan, K. L. Lancaster, J. E. Mitchell et al., "Healthrelated quality of life in morbidly obese patients: effect of gastric bypass surgery," Obesity Surgery, vol. 12, no. 6, pp. 773$780,2002$.

[9] L. Sjöström, K. Narbro, C. D. Sjöström et al., "Effects of bariatric surgery on mortality in Swedish obese subjects," New England Journal of Medicine, vol. 357, no. 8, pp. 741-752, 2007.

[10] M. A. Maggard, L. R. Shugarman, M. Suttorp et al., "Metaanalysis: surgical treatment of obesity," Annals of Internal Medicine, vol. 142, no. 7, pp. 547-559, 2005.

[11] C. K. Huang, Y. C. Lee, C. M. Hung, Y. S. Chen, and C. M. Tai, "Laparoscopic Roux-en-Y gastric bypass for morbidly obese Chinese patients: learning curve, advocacy and complications," Obesity Surgery, vol. 18, no. 7, pp. 776-781, 2008.

[12] P. Habib, J. D. Scrocco, M. Terek, V. Vanek, and J. R. Mikolich, "Effects of bariatric surgery on inflammatory, functional and structural markers of coronary atherosclerosis," American Journal of Cardiology, vol. 104, no. 9, pp. 1251-1255, 2009.

[13] A. E. Dixon, R. E. Pratley, P. M. Forgione et al., "Effects of obesity and bariatric surgery on airway hyperresponsiveness, asthma control, and inflammation," Journal of Allergy and Clinical Immunology, vol. 128, no. 3, pp. 508-515, 2011.

[14] B. Simard, H. Turcotte, P. Marceau et al., "Asthma and sleep apnea in patients with morbid obesity: outcome after bariatric surgery," Obesity Surgery, vol. 14, no. 10, pp. 1381-1388, 2004.

[15] N. Sikka, G. Wegienka, S. Havstad, J. Genaw, A. M. Carlin, and E. Zoratti, "Respiratory medication prescriptions before and after bariatric surgery," Annals of Allergy, Asthma and Immunology, vol. 104, no. 4, pp. 326-330, 2010.

[16] M. Maniscalco, A. Zedda, S. Faraone et al., "Weight loss and asthma control in severely obese asthmatic females," Respiratory Medicine, vol. 102, no. 1, pp. 102-108, 2008.

[17] H. J. Sugerman, R. P. Fairman, P. L. Baron, and J. A. Kwentus, "Gastric surgery for respiratory insufficiency of obesity," Chest, vol. 90, no. 1, pp. 81-86, 1986.

[18] P. S. Thomas, E. R. T. C. Owen, G. Hulands, and J. S. Milledge, "Respiratory function in the morbidly obese before and after weight loss," Thorax, vol. 44, no. 5, pp. 382-386, 1989.

[19] P. Weiner, J. Waizman, M. Weiner, M. Rabner, R. Magadle, and D. Zamir, "Influence of excessive weight loss after gastroplasty for morbid obesity on respiratory muscle performance," Thorax, vol. 53, no. 1, pp. 39-42, 1998.

[20] A. Dávila-Cervantes, G. Domínguez-Cherit, D. Borunda et al., "Impact of surgically-induced weight loss on respiratory function: a prospective analysis," Obesity Surgery, vol. 14, no. 10, pp. 1389-1392, 2004.
[21] H. El-Gamal, A. Khayat, S. Shikora, and J. N. Unterborn, "Relationship of dyspnea to respiratory drive pulmonary function tests in obese patients before and after weight loss," Chest, vol. 128, no. 6, pp. 3870-3874, 2005.

[22] A. N. C. Santana, R. Souza, A. P. Martins, F. Macedo, A. Rascovski, and J. M. Salge, "The effect of massive weight loss on pulmonary function of morbid obese patients," Respiratory Medicine, vol. 100, no. 6, pp. 1100-1104, 2006.

[23] C. Martí-Valeri, A. Sabaté, C. Masdevall, and A. Dalmau, "Improvement of associated respiratory problems in morbidly obese patients after open Roux-en-Y gastric bypass," Obesity Surgery, vol. 17, no. 8, pp. 1102-1110, 2007.

[24] N. T. Nguyen, M. W. Hinojosa, B. R. Smith, J. Gray, and E. Varela, "Improvement of restrictive and obstructive pulmonary mechanics following laparoscopic bariatric surgery," Surgical Endoscopy and Other Interventional Techniques, vol. 23, no. 4, pp. 808-812, 2009.

[25] Y. F. Wei, W. K. Tseng, C. K. Huang, C. M. Tai, C. F. Hsuan, and H. D. Wu, "Surgically induced weight loss, including reduction in waist circumference, is associated with improved pulmonary function in obese patients," Surgery for Obesity and Related Diseases, vol. 7, no. 5, pp. 599-604, 2011.

[26] J. P. Kress, A. S. Pohlman, J. Alverdy, and J. B. Hall, "The impact of morbid obesity on oxygen cost of breathing (VO(2RESP)) at rest," American Journal of Respiratory and Critical Care Medicine, vol. 160, no. 3, pp. 883-886, 1999.

[27] D. A. Beuther and E. R. Sutherland, "Overweight, obesity, and incident asthma: a meta-analysis of prospective epidemiologic studies," American Journal of Respiratory and Critical Care Medicine, vol. 175, no. 7, pp. 661-666, 2007.

[28] R. Chen, H. Tunstall-Pedoe, C. Bolton-Smith, M. K. Hannah, and C. Morrison, "Association of dietary antioxidants and waist circumference with pulmonary function and airway obstruction," American Journal of Epidemiology, vol. 153, no. 2, pp. 157-163, 2001.

[29] H. M. Ochs-Balcom, B. J. B. Grant, P. Muti et al., "Pulmonary function and abdominal adiposity in the general population," Chest, vol. 129, no. 4, pp. 853-862, 2006.

[30] D. Canoy, R. Luben, A. Welch et al., "Abdominal obesity and respiratory function in men and women in the EPIC-Norfolk study, United Kingdom," American Journal of Epidemiology, vol. 159, no. 12, pp. 1140-1149, 2004.

[31] H. Santana, E. Zoico, E. Turcato et al., "Relation between body composition, fat distribution, and lung function in elderly men," American Journal of Clinical Nutrition, vol. 73, no. 4, pp. 827-831, 2001.

[32] S. G. Wannamethee, A. G. Shaper, and P. H. Whincup, "Body fat distribution, body composition, and respiratory function in elderly men," American Journal of Clinical Nutrition, vol. 82, no. 5, pp. 996-1003, 2005.

[33] L. C. Collins, P. D. Hoberty, J. F. Walker, E. C. Fletcher, and A. N. Peiris, "The effect of body fat distribution on pulmonary function tests," Chest, vol. 107, no. 5, pp. 1298-1302, 1995.

[34] J. A. Torquato, J. J. Jaber Lucato, T. Antunes, and C. V. Barbas, "Interaction between Intra-Abdominal pressure and PositiveEnd expiratory pressure," Clinics, vol. 64, no. 2, pp. 105-112, 2009.

[35] H. Sugerman, A. Windsor, M. Bessos, and L. Wolfe, "Intraabdominal pressure, sagittal abdominal diameter and obesity comorbidity," Journal of Internal Medicine, vol. 241, no. 1, pp. 71-79, 1997.

[36] D. M. Lambert, S. Marceau, and R. A. Forse, "Intra-abdominal pressure in the morbidly obese," Obesity Surgery, vol. 15, no. 9, pp. 1225-1232, 2005. 
[37] S. Guerra, D. L. Sherrill, C. Venker, C. M. Ceccato, M. Halonen, and F. D. Martinez, "Morbidity and mortality associated with the restrictive spirometric pattern: a longitudinal study," Thorax, vol. 65, no. 6, pp. 499-504, 2010.

[38] R. L. Jones and M. M. U. Nzekwu, "The effects of body mass index on lung volumes,” Chest, vol. 130, no. 3, pp. 827-833, 2006.

[39] V. Sekhri, F. Abbasi, C. W. Ahn, L. J. DeLorenzo, W. S. Aronow, and D. Chandy, "Impact of morbid obesity on pulmonary function," Archives of Medical Science, vol. 4, no. 1, pp. 66-70, 2008.

[40] Y. F. Wei, H. D. Wu, C. Y. Chang et al., "The impact of various anthropometric measurements of obesity on pulmonary function in candidates for surgery," Obesity Surgery, vol. 20, no. 5, pp. 589-594, 2010.

[41] J. Bande, J. Clement, and K. P. Van De Woestijne, "The influence of smoking habits and body weight on vital capacity and FEV1 in male air force personnel: a longitudinal and crosssectional analysis," American Review of Respiratory Disease, vol. 122, no. 5 I, pp. 781-790, 1980.

[42] D. W. Dockery, J. H. Ware, and B. G. Ferris, "Distribution of forced expiratory volume in one second and forced vital capacity in healthy, white, adult never-smokers in six U.S. cities," American Review of Respiratory Disease, vol. 131, no. 4, pp. 511-520, 1985.

[43] I. Rubinstein, N. Zamel, L. DuBarry, and V. Hoffstein, "Airflow limitation in morbidly obese, nonsmoking men," Annals of Internal Medicine, vol. 112, no. 11, pp. 828-832, 1990.

[44] Y. Chen, S. L. Horne, and J. A. Dosman, "Body weight and weight gain related to pulmonary function decline in adults: a six year follow up study," Thorax, vol. 48, no. 4, pp. 375-380, 1993.

[45] E. E. Frezza, K. O. Shebani, J. Robertson, and M. S. Wachtel, "Morbid obesity causes chronic increase of intraabdominal pressure," Digestive Diseases and Sciences, vol. 52, no. 4, pp. 1038-1041, 2007.

[46] Y. Chen, D. Rennie, Y. F. Cormier, and J. Dosman, "Waist circumference is associated with pulmonary function in normalweight, overweight, and obese subjects," American Journal of Clinical Nutrition, vol. 85, no. 1, pp. 35-39, 2007.

[47] W. Ladosky, M. A. M. Botelho, and J. P. Albuquerque, "Chest mechanics in morbidly obese non-hypoventilated patients," Respiratory Medicine, vol. 95, no. 4, pp. 281-286, 2001.

[48] H. Sahebjami and P. S. Gartside, "Pulmonary function in obese subjects with a normal FEV1/FVC ratio," Chest, vol. 110, no. 6, pp. 1425-1429, 1996.

[49] L. S. Inselman, L. B. Padilla-Burgos, S. Teichberg, and H. Spencer, "Alveolar enlargement in obesity-induced hyperplastic lung growth," Journal of Applied Physiology, vol. 65, no. 5, pp. 2291-2296, 1988.

[50] M. Krotkiewski, P. Bjorntorp, L. Sjostrom, and U. Smith, "Impact of obesity on metabolism in men and women. Importance of regional adipose tissue distribution," Journal of Clinical Investigation, vol. 72, no. 3, pp. 1150-1162, 1983.

[51] R. I. Harik-Khan, R. A. Wise, and J. L. Fleg, "The effect of gender on the relationship between body fat distribution and lung function," Journal of Clinical Epidemiology, vol. 54, no. 4, pp. 399-406, 2001.

[52] E. M. Harman, J. W. Wynne, and A. J. Block, "The effect of weight loss on sleep-disordered breathing and oxygen desaturation in morbidly obese men," Chest, vol. 82, no. 3, pp. 291294, 1982.
[53] G. S. Zavorsky, D. J. Kim, J. L. Sylvestre, and N. V. Christou, "Alveolar-membrane diffusing capacity improves in the morbidly obese after bariatric surgery," Obesity Surgery, vol. 18, no. 3, pp. 256-263, 2008.

[54] B. W. Oppenheimer, R. Macht, and R. M. Goldring, "Distal airway dysfunction in obese subjects corrects after bariatric surgery," Surgery for Obesity and Related Diseases. In press. 


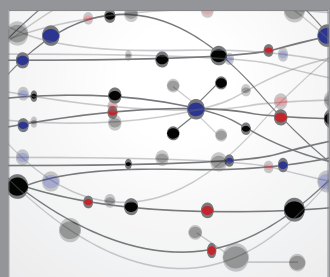

The Scientific World Journal
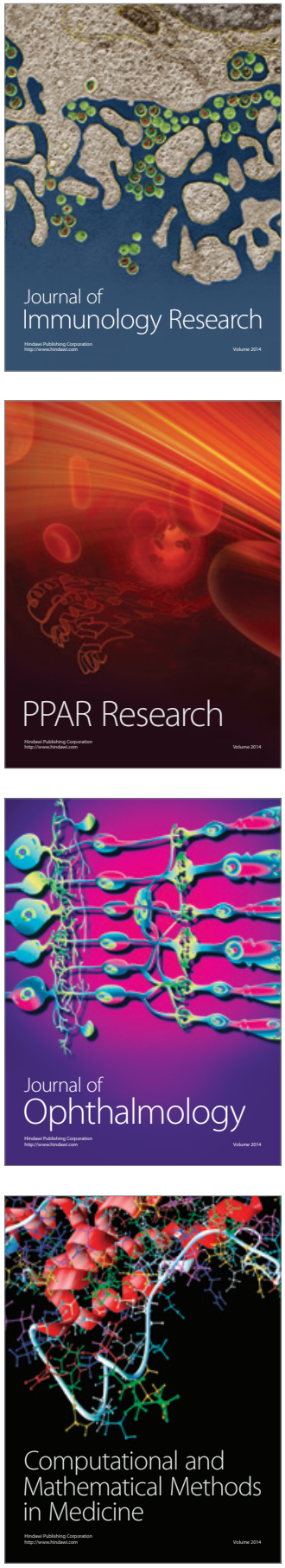

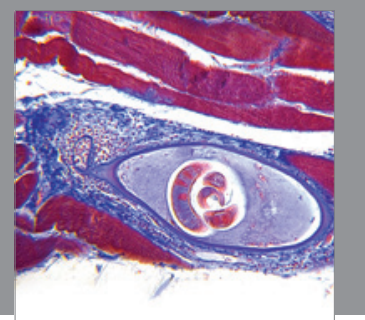

Gastroenterology

Research and Practice
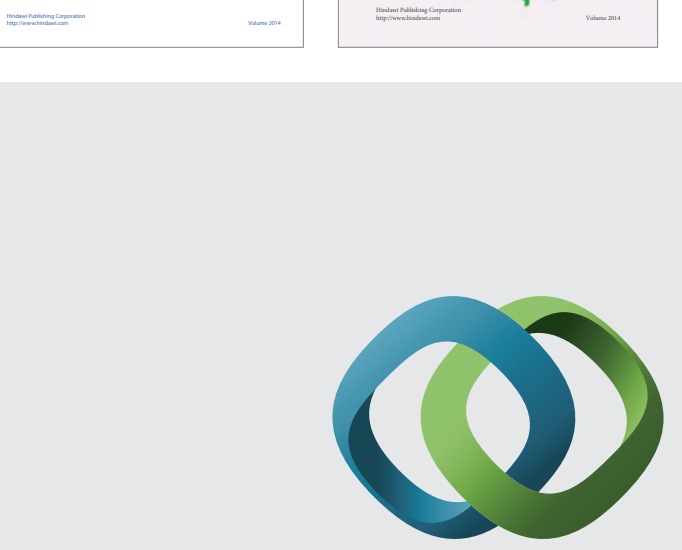

\section{Hindawi}

Submit your manuscripts at

http://www.hindawi.com
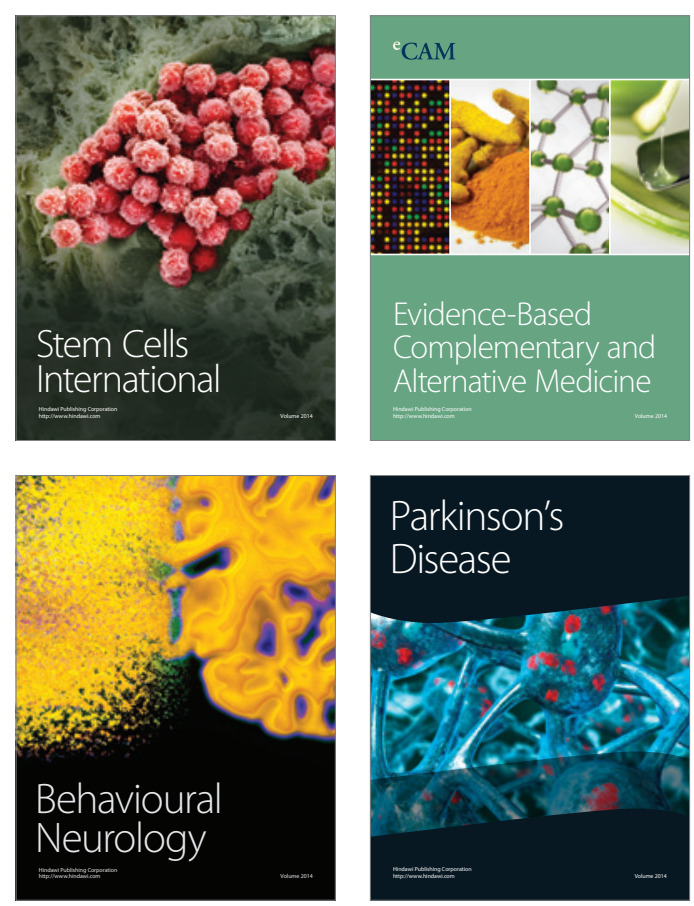

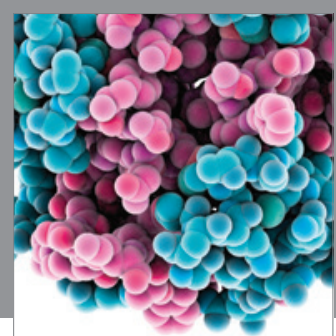

Journal of
Diabetes Research

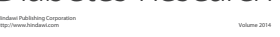

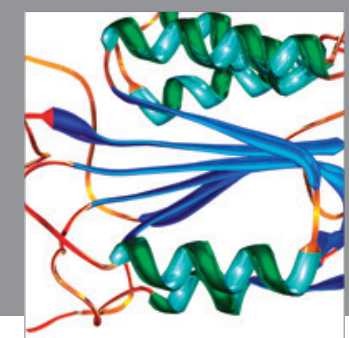

Disease Markers
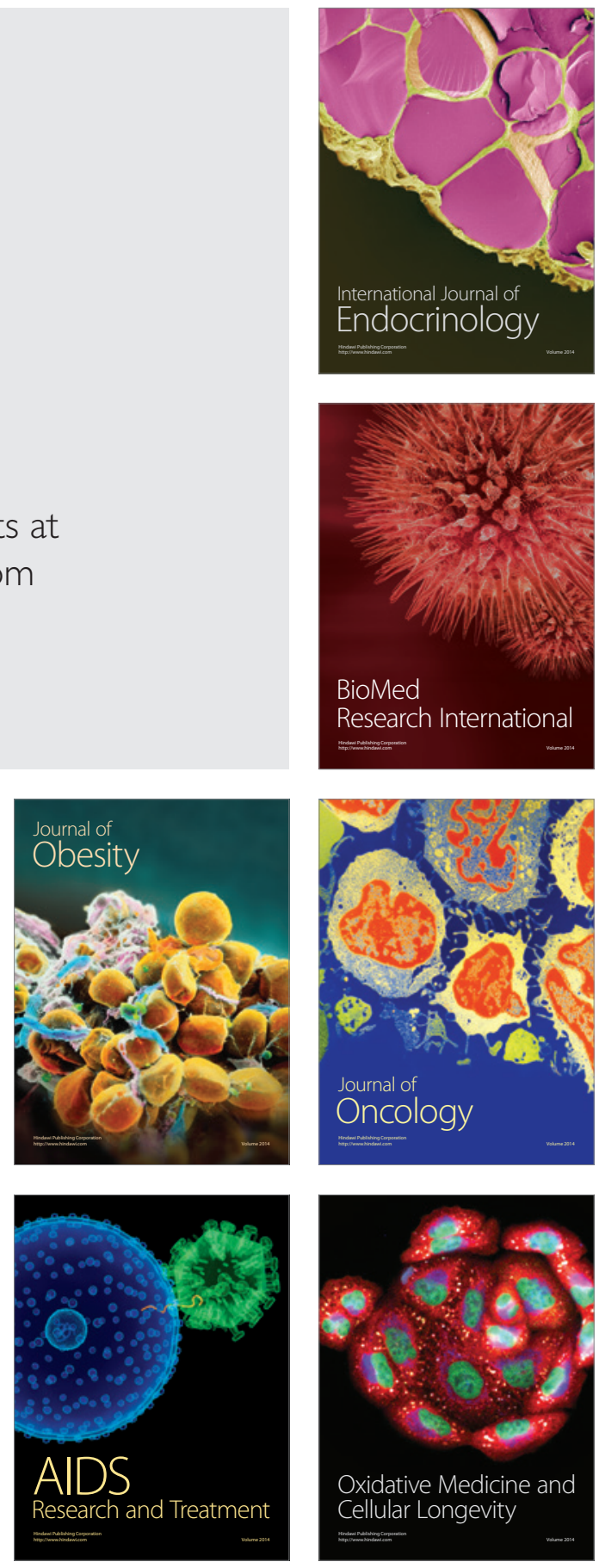